\title{
Extent of Public High Schools Principals' Practice for Organizational Justice in Their Schools from Teachers' Perspective in Alkarak Governorate 2018
}

\author{
Dr- hind khaled domour \\ dr- lena mohammd bsharat \\ Noura Ali jadallah
}

\begin{abstract}
The study aimed to identify the extent of public high schools principals' practice for organizational justice in their schools from teachers' perspective in Alkarak governorate. The sample of the study included ( 309 ) male and female teachers which was randomly selected from the population of the study that consisted of ( 2754 ) male and female teachers. To achieve the goals of the study, the researcher developed a 28 -items questionnaire for organizational justice practice and was checked for reliability and consistency. Results indicated that the extent of public high schools principals' practice for organizational justice in their schools in Alkarak governorate from teachers' perspective was medium and there were significant statistical differences at the level $\alpha \leq 0.05$ based on the variable of gender and these differences were in favor of females. Results also indicated significant statistical differences at the level $\alpha \leq 0.05$ based on the variable of experience in favor of those with experience of 5 to less than 10 years experience and finally, the results indicated significant statistical differences at the level $\alpha \leq 0.05$ based on the variable of the educational qualification in favor of bachelor degree. The study recommended for high public schools principals in Alkarak governorate to practice more organizational justice with teachers and to be interested with experienced teachers with higher educational qualifications.
\end{abstract}

Keywords: Organizational Justice, Public High Schools, School Principals .

DOI: $10.7176 / \mathrm{JEP} / 10-2-02$

\section{Background}

The great scientific advancement the $21^{\text {st }}$ century witnesses in the various life aspects - including the educational field - impose the need for establishing a totally different educational system from the existed ones. An educational system that is basically based on qualifying high skilled staff and making available methods that enable it to solve the problems face the system and the community.

The success of any organization depends on achieving its goals and the quality of the human resource performance, and the performance of individuals is greatly related to the justice practiced upon them from superiors for its great role within work environment as it was indicated that subordinates realization for organizational justice positively affects several organizational outputs such as workers' attitudes that include job satisfaction, intentions to leave work and organizational commitment in addition to affecting workers' behaviors such as organizational citizenship and absence from work ( John, 1999 ).

Balassiano and Salles confirmed that organizational justice has great benefits for both organizations and workers alike, these benefits include the increased organizational trust and organizational commitment as the leader's administrative commitment to professional behavior and a moral system must be ideal and applicable by all educational administrators which in turn requires his her administrative behavior to be moral and belong to society ( Dwani, 2013 ). Among the most important morals a leader has to commit to is justice, as fair leader treats everyone equally with no discrimination in hiring, promotion, training and any other treatment at work based on the race pr the gender of the applicant for work (Alsakarneh, 2009).

Carolina ( 2005 ) sees that workers within administrative work environments divide organizational justice based on three categories of treatment. The $1^{\text {st }}$ one represents the outputs the receive from the organization represented by the distributive justice, and distributive justice indicates the realized justice by the organization's individuals as resources distribution by the organization and each individual receives, and also indicates the workers' feelings of the justice in distributing the organizational outputs, and distributive justice is classified as seen by Koopmann ( 2003 ) into three types : 1- equity : unless the returns are distributed on workers based on the degree of contribution, the part time worker won't be equal to that of full time work regarding wages ( returns ), 2- equality : returns are distributed on workers with no discrimination as this is based on knowledge, skill and productivity and hence each has equal opportunities, and 3- need : distribution here is based on the need, for example, a mother of two or more children deserves an increase in salary compared to a mother of one child. The $2^{\text {nd }}$ one represents the official policies or the processes based on which these outputs are distributed ( procedural justice), procedural justice means the extent of individuals' feeling that the followed procedures and processes for rewards' determination ( outputs ) are fair ( Rego and Cunha, 2006 ), In addition to distribution justice which indicates the fair processes followed customize decisions fpr rewards' distribution 
( Begum, 2005 ).

The $3^{\text {rd }}$ type includes the personal treatment with workers (interactive justice ) which means the extent of workers feeling of the justice of treatment they receive when procedures are applied, interactive justice also indicates the way the administration acts toward individuals which is basically related to administrators' way of treating subordinates ( Lee, 2000 ).

Organizational justice importance and its effective role in achieving the workers' best achievement and performance arise from their feelings of justice, equality and equity and this has a clear influence in the educational process as principal's justice directly affects teachers' behavior which in turn increases their cooperation and interaction positively on both the official and the personal levels ( Albakkar, 2012).

Hassan ( 2002 ) indicated that organizational justice ingredients are achieved when individuals within an organization understand the standard of receiving a reward and by developing various perspectives regarding their financial and moral rewards in addition to adopting behaviors based on their realization for the reality whether the feeling of justice or not.

Rahim ( 2000 ) pointed out that principals' practice for organizational justice within their educational institutions is positively reflected on workers and teachers practices, their job performance, their belonging in addition to the increase in the organizational loyalty levels and professional motivation among them.

Alkhaldi and Salamah ( 2014 ) a study that aimed to identify the organizational justice among high schools' principals in Almafraq governorate in Jordan and its relationship[ with teachers' organizational loyalty in these schools. The sample of the study was selected using the stratified random method and was consisted of ( 648 ) secondary stage male and female teachers from Almafraq directorates of education, and questionnaire was utilized for data collection and to achieve the goals of the study. Results indicated that the extent of organizational justice application among high schools principals in Almafraq from teachers' perspective was high and also indicated significant statistical differences that are attributed to the variable of gender and there were no significant statistical differences that are attributed to the educational qualification variable.

The study of Burns and Dipaola ( 2013 ) aimed to identify the correlation between organizational justice , organizational citizenship and students' achievement in high schools. The study was conducted on a sample of ( 1019 ) male and female students of various reaches and nationalities in Virginia. To achieve the goals of the study, the questionnaire was utilized for data collection. Results indicated a positive correlation between organizational justice and organizational citizenship at high schools but no correlation was indicated between organizational and students' achievement.

Yilmaz and Altinkurt ( 2012 ) investigated the nature of the relationship between school leadership behaviors in organizational justice and organizational trust. The sample of the study was consisted of ( 271 ) male and female teachers from Kütahya province in Turkey. Questionnaire was utilized for data collection and for achieving the goals of the study. Results indicated high levels of organizational justice among high schools principals and teachers, and there was a high positive correlation between principals' school leadership behaviors and teachers' perspectives toward organizational justice and trust in graduates.

Alhumaidi ( 2012 ) studied the degree of practicing organizational justice and the extent of organizational commitment and job satisfaction among female principals at Jeddah high schools from the perspective of both principals and female teachers in Jeddah governorate whom were ( 400 ) participants. The researcher used questionnaire for data collection. Results indicated that high schools' female principal practice for organizational justice was high and indicated differences in the degree tp which female principals practice organizational justice from female teachers' perspectives and these differences are attributed to the educational qualification variable in favor of those holding the M.A degree . Results also indicated no significant statistical differences in female principals' practice for organizational justice from the perspective of both female teachers and principals that are attributed to the study variables ( experience, specialty and marital status ).

Alma'aytah ( 2005 ) conducted a study to identify teachers' perspectives toward the extent of high schools principals' practice in Jordan for organizational justice in addition to identifying principals' perspectives toward teachers' level of organizational citizenship behavior. The sample of the study was consisted of ( 72 ) male and female principals and ( 1010$)$ male and female teachers . Both the organizational justice and organizational questionnaires were used. Results indicated that the level of high schools principals' practice for organizational justice in Jordan came medium in general based on teachers' perspectives and also indicated statistical differences in organizational justice from teachers' perspectives that are attributed to the educational qualification variable in favor of the M.A degree and above while no differences were indicated for both experience and gender variables.

Coliski ( 2003 ) developed an instrument to measure the perceptions of Organizational Justice at Middle Schools and applied it on ( 408 ) , male and female students in the USA schools. To achieve the goals of the study. The 29-quesionnaire of organizational justice was developed. Results indicated a correlation between student's lack of feeling for organizational justice with its all dimensions and the conflict and violence size among students, results also indicated significant statistical differences in students' concept of organizational 
justice that are attributed to the variable of gender in favor of female students.

\section{Comments on Early Studies :}

Early studies have addressed organizational justice among various communities and most of them has focused on public schools and some has related organizational justice to students' achievement and others related it to organizational loyalty. These studies varied in their goals and results while the current study is distinguished by investigating the extent of public high schools principals' practice for organizational justice in their schools from their perspective in Alkarak governorate, this study is similar with the early studies in that it utilized questionnaire for data collection and the researcher has benefited from these early studies in developing the tool of the current study in addition to utilizing them in the theoretical literature review.

\section{Statement of the Problem :}

The problem of the study is determined by identifying the extent of public high schools principals' practice for organizational justice in their schools from their perspective in Alkarak governorate and in answering the following research questions:

1- To which extent do public high schools principals' practice organizational justice in their schools from teachers' perspective in Alkarak governorate?

2- Are there significant statistical differences at the level $\alpha \leq 0.05$ in participants' responses based on the study variables ( gender, educational qualification and experience )?

\section{Goals of the Study:}

This study aims to achieve the following goals:

- Identifying the extent of public high schools principals' practice for organizational justice in their schools from teachers' perspective in Alkarak governorate.

- Identifying any significant statistical differences at the level $(\alpha \leq 0.05)$ in participants' responses on the extent of public high schools principals' practice for organizational justice in their schools from teachers' perspective in Alkarak governorate based on the study variables ( gender, educational qualification and experience )

\section{Significance of the Study}

The significance of this study arises from that it is hoped that it will benefit officials and decision makers in the ministry of education to identify the extent of public high schools principals' practice for organizational justice in their schools in Alkarak governorate and in benefiting principals in improving their practice for organizational justice in their schools.

\section{Limitations of the Study}

- Human limitations : teachers in Alkarak governorate public high schools.

- Objective limitations : organizational justice.

- Spatial limitations : Alkarak governorate.

- Time limitations : the school academic year 201612017.

Results of the study were determined by the reliability and consistency extent of the tool used here and respondents' honesty and the findings of this study are generalized only on similar populations .

\section{Conventional and Procedural Definitions}

- Organizational Justice : it is the way by which an individual judges the justice of the method used by the administrator on both the career and human levels, and it is a relative concept that is determined in light of what the employee realize of the outputs' integrity and objectivity within an organization ( Abu Nada, 2007 ).

Procedurally, organizational justice is the degree or extent to which public high schools principal's practice it based on the participants' responses on the organizational justice questionnaire developed for this purpose.

\section{Methodology and Procedures}

Methodology and procedures address a description for the study approach, its population and sample , the tool utilized and its reliability and consistency, the variables of the study, the procedures, and the statistical methods used to answer the research questions.

\section{Methodology}

The study followed the descriptive survey approach with the aim of identifying public high schools principals' practice for organizational justice from teachers' perspective in Alkarak governorate through the teachers' 
responses on the items of the questionnaire developed for this purposes.

\section{The Study Population}

The population of the study consisted of all public high schools' male and female teachers in Alkarak governorate whom were 2754 teachers ( 1451 female and 1303 male teachers ) based on the statics of the Jordanian Ministry of Education for the school academic year ( 2016 2017 ) in seven directorates of education on Alkarak. Table ( 1 ) shows the distribution of the study population ( male and females teachers ) based on the directorate of education and gender in Alkarak governorate.

\section{Sample of the Study :}

The sample of the study was selected using the stratified relative random method from public high schools' male and female teachers and was consisted of ( 309 ) male and female teachers which is $11 \%$ of the study population as shown in table $(2)$.

Table ( 2 )

The study sample distribution based on the levels of variables

\begin{tabular}{|c|c|c|c|}
\hline Variable & Level & Number & Total \\
\hline \multirow[t]{2}{*}{ Gender } & Male & 151 & \multirow[b]{2}{*}{309} \\
\hline & Female & 158 & \\
\hline \multirow[t]{3}{*}{ Experience } & Less than 5 years & 108 & \multirow{3}{*}{309} \\
\hline & $\begin{array}{c}\text { From } 5 \text { to less than } 10 \\
\text { years }\end{array}$ & 147 & \\
\hline & 10 years and above & 54 & \\
\hline \multirow[t]{2}{*}{ Educational Qualification } & Bachelor & 281 & \multirow[t]{2}{*}{309} \\
\hline & Higher Studies & 28 & \\
\hline
\end{tabular}

Study Tool

Based on the theoretical literature and early studies, a two parts- questionnaire was developed where the $1^{\text {st }}$ part included the respondents' personal variables ( gender, educational qualification and experience ) and the $2^{\text {nd }}$ one included the items that measure the extent to which public high schools' principals practice organizational justice , this part included 28 items and the response was based on Likert five points scale ( $5=$ very great , 4= great , $3=$ medium $.2=$ little and $1=$ very little .

\section{Reliability of the Study Tool}

To check for the reliability of the tool, it was subscribed in its initial version to a group of 16 experienced and specialists in the field of educational administration and assessment and evaluation to check for the clearness of items, the appropriate linguistic formulation and to which extent these items belong to the dimension the supposed to measure. The researcher then took the jury's perceptions and recommendations related to reformulation of some items and the agreement of the jury members upon each item with a percentage of $(80 \%)$ and more was regarded as an indicator for the reliability of the items. In its final version, the tool consisted of 28 items without any omits.

\section{Consistency of the Study Tool}

Consistency of the tool was calculated using the test and retest method as the tool was applied on a pilot sample of ( 20 ) male and female teachers from the population of the study but other than its original sample and the tool was reapplied on the same pilot sample two weeks later, then Pearson correlations were calculated for the pilot sample estimations on the tool as whole between the two applications and consistency was ( 0.95 ) which was appropriate for the purpose of conducting this study. In addition, the Cornbach-Alpha formulation was used to determine the consistency coefficient and it was ( 0.92 ) which is accepted value.

\section{Study Variables}

The study included the following variables :

- Independent variables : gender ( male]female ), educational qualification ( bachelor degree and higher studies ) and experience ( less than 5 years $\backslash 5-10$ years $\backslash$ more than 10 years ).

- Dependent variable : the extent of public high schools principals' practice for organizational justice from teachers' perspective in Alkarak governorate.

\section{Procedures}

The procedures of the study were implemented based on the following steps :

- After reviewing the theoretical literature and early studies on the topic of the study, the study tool was 
developed.

- The official approvals were obtained from the related parties to apply the study on the study population.

- The psychometric properties of the study tool were checked and then it was applied on the sample of the study, and finally data were computerized and the research questions were answered.

\section{Statistical Treatment :}

To answer the research questions in this study, the following statistical methods were used :

- For the first research question, means and standard deviations were used.

- For the second research question, the following statistical methods were utilized based on the study variables : a- t-test for two independent samples to identify significance of the differences based on the gender variable. b- One-Way ANOVA to identify the significance of the differences based on both the educational qualification and experience variables.

c- The Scheffe Test to identify the differences attribution based on both the experience and educational qualification variables.

\section{Results :}

Results related to the $1^{\text {st }}$ research question : To which extent do public high schools principals' practice organizational justice in their schools from teachers' perspective in Alkarak governorate?

To answer this question, means and SDs were calculated then the rank and the extent of public high schools principals' practice for organizational justice from teachers' perspective in Alkarak governorate were determined as shown in table ( 3 ).

Table (3)

Means, SDs , ranks and extent of public high schools principals' practice for organizational justice from teachers' perspective in Alkarak governorate in descending order

\begin{tabular}{|c|c|c|c|c|c|}
\hline No & Item & Mean & SD & Rank & $\begin{array}{l}\text { Practice } \\
\text { Level }\end{array}$ \\
\hline 7 & $\begin{array}{l}\text { The principal distributes rewards on employees based on } \\
\text { achievement and effort. }\end{array}$ & 5.58 & 1.56 & 1 & High \\
\hline 17 & $\begin{array}{l}\text { The principal is interested in resolving organizational conflicts fairly } \\
\text { between teachers. }\end{array}$ & 5.58 & 1.59 & 1 & High \\
\hline 14 & $\begin{array}{l}\text { The principal previously makes clear the evaluation standards for } \\
\text { teachers. }\end{array}$ & 5.42 & 1.76 & 3 & High \\
\hline 12 & $\begin{array}{l}\text { The principal attempts to persuade teachers that the decisions } \\
\text { helmakes are in favor of the work. }\end{array}$ & 5.31 & 1.57 & 4 & High \\
\hline 3 & The principal fairly distrubutes tasks among teachers. & 5.21 & 1.51 & 5 & High \\
\hline 28 & The principal evaluates performance clearly for all workers. & 5.18 & 1.81 & 6 & High \\
\hline 10 & $\begin{array}{l}\text { The principal allows teachers the oppurtunity to appeal his } \backslash \text { her } \\
\text { decisions. }\end{array}$ & 5.12 & 1.59 & 7 & High \\
\hline 27 & $\begin{array}{l}\text { The principal makes available illustrative information about the } \\
\text { decisions helshe makes. }\end{array}$ & 5.10 & 1.70 & 8 & High \\
\hline 16 & $\begin{array}{l}\text { The principal constructs positive work relationships among the } \\
\text { school staff. }\end{array}$ & 5.06 & 1.64 & 9 & High \\
\hline 21 & $\begin{array}{l}\text { The principal traets workers with respect when making a decision } \\
\text { related to them in work. }\end{array}$ & 5.00 & 1.86 & 10 & Medium \\
\hline 15 & $\begin{array}{l}\text { The principal develops cooperation among teachers so as to work } \\
\text { with one team spirit. }\end{array}$ & 4.93 & 1.72 & 11 & Medium \\
\hline 19 & The principal supports teachers to evaluate themselves. & 4.92 & 1.72 & 12 & Medium \\
\hline 24 & $\begin{array}{l}\text { The principal evaluates the teacher according to his her performance } \\
\text { and achievement through the school academic year. }\end{array}$ & 4.91 & 1.74 & 13 & Medium \\
\hline 26 & $\begin{array}{l}\text { The principal constructs and designs training programs for teachers } \\
\text { based on the outputs of their performance evaluation. }\end{array}$ & 4.90 & 1.62 & 14 & Medium \\
\hline 9 & $\begin{array}{l}\text { The principal discusses with teachers the outputs of the decisions } \\
\text { helshe makes. }\end{array}$ & 4.89 & 1.55 & 15 & Medium \\
\hline 5 & $\begin{array}{l}\text { The principal takes into consideration the workers' circumstances } \\
\text { when making decisions related to them. }\end{array}$ & 4.85 & 1.88 & 16 & Medium \\
\hline 23 & $\begin{array}{l}\text { The principal shows interest in emolpyee's rights when making a } \\
\text { decision that relates to this employee. }\end{array}$ & 4.85 & 1.64 & 16 & Medium \\
\hline
\end{tabular}




\begin{tabular}{|l|l|l|l|l|l|}
\hline No & \multicolumn{1}{|c|}{ Item } & Mean & SD & Rank & $\begin{array}{l}\text { Practice } \\
\text { Level }\end{array}$ \\
\hline 22 & $\begin{array}{l}\text { The principal takes into consideration the workers circumstances } \\
\text { when making a decision relates to them. }\end{array}$ & 4.79 & 1.59 & 18 & Medium \\
\hline 4 & The mandated tasks for teachers are appropriate for them. & 4.77 & 1.66 & 19 & Medium \\
\hline 11 & $\begin{array}{l}\text { The principal makes his her decisions based on a previously collected } \\
\text { data and information. }\end{array}$ & 4.77 & 1.67 & 19 & Medium \\
\hline 2 & $\begin{array}{l}\text { The principal discusses the teacher about the decision related to this } \\
\text { teacher. }\end{array}$ & 4.75 & 1.68 & 21 & Medium \\
\hline 18 & $\begin{array}{l}\text { The principal explicitly makes clear for teachers his her impressions } \\
\text { about the workflow. }\end{array}$ & 4.69 & 1.78 & 22 & Medium \\
\hline 13 & $\begin{array}{l}\text { The principal applies the teachers related decisions on all with no } \\
\text { exceptions. }\end{array}$ & 4.55 & 1.74 & 23 & Medium \\
\hline 8 & $\begin{array}{l}\text { The principal makes clear for the teachers their rights and duties. } \\
6\end{array}$ & 4.50 & 1.70 & 24 & Medium \\
\hline 20 & $\begin{array}{l}\text { The principal distributes tasks based on teachers' qualifications. } \\
\text { performance. }\end{array}$ & 4.43 & 1.88 & 25 & Medium \\
\hline 1 & The principal mandates some of his her powers to teachers. & 4.40 & 1.82 & 26 & Medium \\
\hline 25 & $\begin{array}{l}\text { The principal makes workers feel justice and fair in rewards' } \\
\text { distribution. }\end{array}$ & 4.11 & 1.91 & 27 & Medium \\
\hline \multicolumn{2}{|l|}{ Total } & 4.02 & 1.79 & 28 & Medium \\
\hline
\end{tabular}

From table (3) above, it is noticed that the and extent of public high schools principals' practice for organizational justice from teachers' perspective in Alkarak governorate was medium as the total score mean was $(4,88)$ with a SD of $(1,34)$. The items of the tool came at both a high and medium levels as means ranged from $(5,58)$ to $(4,02)$ with both the $7^{\text {th }}$ item " the principal distributes rewards on workers based on effort and achievement " and the $17^{\text {th }}$ item " the principal is concerned about resolving conflicts between teachers fairly " first with a mean of ( 5,58 ) and SDs of (1,56) and ( 1,59) respectively and at a high level. Before the last, came the 1st item " the principal mandates some of hislher responsibilities and powers to teachers " with a mean of $(4,11)$ and an SD of ( 1,91) at a medium level, and finally came the 25th item " the principal makes workers feel justice in receiving rewards " with a mean of (4,02) and an $\operatorname{SD}$ of (1,79) at a medium level. Principal who fairly treats teachers distributes rewards based on effort and achievement exerted by teachers, so such principal previously makes clear the performance evaluation standards and is interested in resolving organizational conflicts among teachers Without prejudice and [positively constructs work relationships among the staff at school. The high score obtained by principals positively reflects the teachers' feelings toward them and this result can be attributed to the real justice teachers' touch from their principals in public high schools in Alkarak governorate as principal are able to find appropriate work environment for workers which makes them do their tasks. The extent of practicing organizational justice has dropped into a medium level in the rest of items and the total score, and this indicates that principal do not treat teachers with great respect when making a decision related to them and may do not construct training programs based on the results of performance evaluation and do not seriously discuss the results of the decisions helshe makes with teachers and may pay no attention to the workers' conditions in distributing the tasks mandated to teachers. This result may be attributed to the nature of public high schools where the principal is restricted to instructions from decision makers at the school which makes himlher less able to interpret the procedures and decisions helshe makes for teachers. This result can also be attributed to that public high schools' principals treat teachers with much toughness looking for the final outputs paying no attention to teachers circumstances and conditions and the extent the decisions they make affect them. This result is in agreement with Alma'aytah study but not with other studies such as Alkhaldi and Salameh ( 2014 ), Yilmaz, K and Altinkurt ( 2012 ) AND Alhumaidi ( 2012 ). Results related to the $2^{\text {nd }}$ research question : Are there significant statistical differences at the level $\alpha \leq 0.05$ in participants' responses based on the study variables ( gender, educational qualification and experience ) ?

1- Gender variable : means and SDs for the extent of public high schools principals' practice for organizational justice in Alkarak governorate were calculated and the t-test for independent samples was used for two independent samples to check for the differences based on the variable of gender as shown in table (4). 
Table (4)

means, SDs and $t$ value of independent samples for differences in for the extent of public high schools principals' practice for organizational justice in Alkarak governorate based on the variable of gender

\begin{tabular}{|r|l|c|c|c|c|c|c|}
\hline & Gender & No & Mean & SD & T value & $\begin{array}{c}\text { Freedom } \\
\text { scores }\end{array}$ & Sig \\
\hline $\begin{array}{r}\text { Organizational } \\
\text { Justice }\end{array}$ & Male & 151 & 4.63 & 1.309 & -3.301 & 307 & 0.001 \\
\cline { 2 - 9 } & Female & 158 & 5.12 & 1.325 & & & \\
\hline
\end{tabular}

Results in table (4) indicates significant statistical differences at the level $\alpha \leq 0.05$ in the extent of public high schools principals' practice for organizational justice in Alkarak governorate based on the variable of gender based on calculated $t$ value of (3-. 301) and a significance level of ( 0.001$)$ and these differences were in favor of female principals. This result may be attributed to that female principals are less confrontational than male principals as they accept the work laws and conditions due to their governmental conditions. Other attribution for this result is that male teachers may usually seek the school that offers them appropriate income so they more mobile from a school to another and this makes them feel less justice than females do. This result is similar to that of Alkhaldi and Salameh ( 2014 ) and Coloski (2003) but not with that of Alma'aytah ( 2005 ).

2- Experience variable : means and SDs for the extent of public high schools principals' practice for organizational justice in Alkarak governorate based on the experience variable were calculated as shown in table (5).

Table (5)

means and SDs for the extent of public high schools principals' practice for organizational justice in Alkarak governorate based on the experience variable

\begin{tabular}{|l|l|c|c|c|}
\hline & Categories & No & Mean & SD \\
\hline \multirow{3}{*}{ Organizational Justice } & Less than 5 years & 108 & 4.78 & 1.288 \\
\cline { 2 - 5 } & From 5 to less than 10 years & 147 & 5.07 & 1.322 \\
\cline { 2 - 5 } & 10 years and above & 54 & 4.55 & 1.415 \\
\cline { 2 - 5 } & Total & 309 & 4.88 & 1.338 \\
\hline
\end{tabular}

from table (5) above, virtual differences can be seen between the means of the extent of public high schools principals' practice for organizational justice in Alkarak governorate based on the experience variable as the highest mean for the total score was $(4,88)$ and those with the experiences of 5 to less than 10 years had the highest mean of ( 5,07) and finally came those with experiences of 10 years and above as their mean was ( 4,55). To determine if these differences between means were statistically significant at the level $\alpha \leq 0.05$, the One-Way ANOVA was utilized and the results are shown in table (6) below .

Table (6)

One-Way ANOVA to determine differences in the extent of public high schools principals' practice for organizational justice in Alkarak governorate based on the experience variable

\begin{tabular}{|l|l|l|l|l|l|c|}
\hline & \multicolumn{1}{|c|}{ Source } & Squares' Sum & Freedom Scores & Squares' Mean & F Value & Sig \\
\hline \multirow{3}{*}{ Organizational Justice } & Among groups & 12.590 & 2 & 6.295 & & \\
\cline { 2 - 5 } & Within groups & 539.024 & 306 & \multirow{2}{*}{1.762} & \multirow{3}{*}{3.574} & 0.029 \\
\cline { 2 - 8 } & Total & 551.615 & 308 & & \\
\hline
\end{tabular}

Results in table (6) indicates significant statistical differences at the level $\alpha \leq 0.05$ in the extent of public high schools principals' practice for organizational justice in Alkarak governorate based on the variable of experience based on calculated $f$ value of ( 3.574 ) with a statistical significance of ( 0.029 ). To identify the differences attribution, the Sheffe post-comparison test was utilized as shown in table ( 7 ).

Table (7)

Sheffe post-comparison test for differences in the extent of public high schools principals' practice for organizational justice in Alkarak governorate based on the variable of experience

\begin{tabular}{|l|l|l|l|l|l|}
\hline & Experience & Mean & $1-5$ & From 5 to less than 10 & 10 and above \\
\hline \multirow{3}{*}{ Organizational Justice } & Less than 5 years & 4.78 & & & \\
\cline { 2 - 7 } & From 5 to less than 10 years & 5.07 & .290 & & \\
\cline { 2 - 6 } & 10 years and above & 4.55 & .230 & .530 & \\
\hline
\end{tabular}

Table (7) above, shows that the difference was in favor of those with an experience of 5 to less than 10 years when their means were compared with the means of those with experiences of less than 5 years and 10 and above years experiences. This result might be attributed to that the category of 5 to less than 10 years experience is the category the most prevalent at schools and the category of less than 5 years isn't desired at public high schools as this category has less experience and obtains less advantages which makes it in a continuous transition between schools seeking justice in treatment. For the category of 19 years of experience and above, this category requires special conditions and privileges that can't be met on most times on public schools due to the policies of 
these schools which leads this category to seek other schools that appreciate the experiences and efforts of those at this category. This result isn't in agreement with that of any other studies .

3- Educational qualification variable : means and SDs for the extent of public high schools principals' practice for organizational justice in Alkarak governorate based on the educational qualification variable were calculated as shown in table (8).

Table (8)

means and SDs for the extent of public high schools principals' practice for organizational justice in

\begin{tabular}{|c|c|c|c|c|}
\hline \multicolumn{5}{|c|}{ Alkarak governorate based on the educational qualification variable } \\
\hline Sequence & Categories & Number & Mean & SD \\
\hline 1 & Bachelor & 281 & 4.99 & 1.27 \\
\hline 2 & Higher Studies & 28 & 4.78 & 1.35 \\
\hline & Total & 309 & 4.88 & 1.31 \\
\hline
\end{tabular}

Table (8) above indicates differences between the means of means and SDs for the extent of public high schools principals' practice for organizational justice in Alkarak governorate based on the educational qualification variable and these differences were in favor of the bachelor degree. This result is attributed to that teachers with bachelor degree are the most effective category in public high schools which means that instructions are closer to them than those with higher degrees who require higher advantages that may not be met in many times. This result also can be attributed to that public high schools principals are more inclined to hire teachers with bachelor degree as they have less requirements compared to higher degrees holders which makes principals make instructions and regulations according teachers with bachelor degree. This result isn't in agreement with the early studies reviewed in this study.

In light of the result of this study, it is recommended to :

- Directing officials to subscribe public high schools principals for training courses and workshops on organizational justice and humanistic management.

- Increasing public high schools principals' attention in Alkarak governorate regarding teachers' categories ( experiences,higher educational qualifications ) and to meet their needs.

\section{References}

Abu Nada, Samya Khamis ( 2007 ) Prevalent Leadership Styles and their Relationship with Organizational Commitment and Felling Justice in Palestinian Ministries at Gaza Strip. Unpublished M.A Thesis. The Islamic University. Gaza. Palestine.

Albakkar, Amani ( 2012 ) Level of Organizational Justice Practiced by Alkarak Governorate Public High Schools' Principals in Relation to the Organizational Trust Level in their Schools from Teachers' Perspective. Unpublished M.A Thesis. Middle East University. Alkarak. Jordan.

Alhumaidi, Manal ( 2012 ) Organizational Justice Among High Schools' Female Principal and its Relationship with Job Satisfaction and Organizational Commitment in Jeddah Governorate.Um Alqura University, Mecca . KSA.

Alkhaldi, Asma' and Salameh, Kayed ( 2014 ) Organizational Justice Among Public High Schools' Principals in Almafraq Governorate and its Relationship with Teachers' Organizational Loyalty in these Schools. Almanarah Journal. 20\2 . p31-57.

Dwani, Kamal ( 2013 ) Educational Leadership . Alkarak. Dar Almasirah for Publication.

Alsakarneh, Bilal ( 2009 ) Work Ethics. Alkarak. Dar Almasirah for Publication.

Alma'aytah , Ahmad ( 2005 ) Extent of Jordanian Public High Schools Principals' Practice for Organizational Justice and its Relationship with Teachers' Organizational Citizenship. ( Unpublished PhD Thesis ). Alakarak Arab University for Higher Studies. Alkarak. Jordan.

Balassiano, M and Salles, D. (2012).Perceptions of Equity and Justice and Their Implications on Affective Organizational Commitment:

A Confirmatory Study in a Teaching and Research Institute. 9(3): 268-286.

Begum, N.(2005). The relationship between social power and organizational citizenship behavior: The meditational role of procedural justice, organizational commitment, and job satisfaction in context of a private commercial bank in Bangladesh, (Unpublished doctoral dissertation), Independent University, Bangladesh, UMI, Pro Quest, Retrieved on 28/5/2017.

Burns W and Dipaola, M. (2013). A Study of Organizational Justice, Organizational Citizenship Behavior, and Student Achievement in High Schools. American Secondary Education. 42(1): 4- 23.

Carolina, M. (2005). Relationship between organizational justice and Burnout at the work until level. Journal of stress management, 12(2): 101- 109.

Coloski, M. (2003). An Instrument to Measure Perceptions of Organizational Justice of Middle Schools, Dissertation Abstract International, 63(8), P.27-55. 
Koopmann, R..(2003).The relationship between perceived organizational justice and organizational citizenship behavior, Retrieved on, www .uwstou .edu /solutions /uwjst / koomann .pdf.

Lee, H. R. (2000). An empirical study of organizational justice as a mediator in the relationships among leadermember exchange and job satisfaction, organizational commitment, and turnover intentions in the lodging industry. (Unpublished dissertation). Virginia Technical University, Blackburg, Virginia . UMI. Pro Quest, Retrieved on $28 / 5 / 2017$.

Rahim, M. (2000). "Do Justice Perceptions influence styles of handling conflict with supervisors? What Justice perceptions, precisely? International Journal of conflict Management, (11): 9-23.

Rego , A., \& Cunha , M.(2006), Organizational justice and citizenship behaviors : A study in a feminine, high power distance culture ,submission of papers for publication, University de Santiago . 3810-193 ,Aveiro. Portugal.UMI. Pro Quest, Retrieved on 28/5/2017.

Yilmaz, K and Altinkurt, Y. (2012). Relationship between the leadership behaviors, organizational justice and organizational trust. Faculty of Education Journal, 41(1): 12-24. 